\title{
Toward A Regional Manpower Demand Model
}

\author{
MichaEL W. BABCOCK*
}

During the Kennedy-Johnson administrations, a lengthy list of national legislation was passed emphasizing the need to forecast occupational demand and supply. Eight major manpower acts were passed in the period 1960-1965 indicating a national commitment to education and training programs designed to adjust to changing labor market demands. However, the general problem of regional manpower forecasting has received little attention from regional scientists. This seems paradoxical in view of the demand from several sources for the informational output of a regional manpower forecasting system. Regional manpower agencies need forecasts in order to anticipate labor market changes that would require changes in training programs. The demand for regional forecasts by these agencies has been considerably increased due to a fundamental shift in national manpower policy. The Comprehensive Employment and Training Act of 1973 gives regional manpower agencies greatly increased latitude in formulating local manpower programs. This decentralization of decision making power will require forecasting of local labor market changes in order to formulate rational policy alternatives.

Regional manpower agencies are not the only source of demand for regional manpower forecasts. Education planners also need regional manpower forecasts in order to anticipate enrollment adjustments and formulate appropriate curriculum changes. In addition to public policy needs, forecasts of regional manpower demand would also prove useful to individuals in formulating career choices and to individual firms in determining the feasibility of expansion plans.

The model presented here is a regional manpower demand forecasting model. Most of the paper is devoted to alternative methods of specifying the model and the advantages and disadvantages associated with each of them. The paper concludes with a discussion of the effect of regional manpower supply "feedback" effects on regional manpower demand forecasts.

\section{THE MODEL}

The model consists of two major components - a regional industry employment demand model, and a regional industry-occupation matrix. The industry employment demand model is a time series multiple regression model, which can be used to develop forecasts of total employment for each regional industry.

The multiple regression model used to determine regional employment by industry is of the following form: ${ }^{1}$

*Assistant Professor, Department of Economics, Kansas State University, Manhattan, Kansas.

Computer Programming Assistant - Alan H. Ringleb, Department of Economics, Kansas State University. 


$$
\begin{aligned}
& \mathrm{E}(\mathrm{REGIND})_{\mathrm{i}}=\mathrm{Bo}+\mathrm{B}_{1} \mathrm{E}(\mathrm{UST})+\mathrm{B}_{2} \mathrm{E}(\mathrm{USI})_{\mathrm{i}}+\mathrm{B}_{3} \mathrm{EX} \\
& +\mathrm{B}_{4} \mathrm{E}(\mathrm{REGT})+\mathrm{B}_{5} \mathrm{t}
\end{aligned}
$$

$\mathrm{E}(\mathrm{REGIND})_{\mathrm{i}}$

$\mathrm{E}(\mathrm{UST})$

$\mathrm{E}(\mathrm{USI})_{\mathrm{i}}$

EX

$\mathrm{E}(\mathrm{REGT})$

t
- Total private wage and salary employment in the ith regional industry

- Total U.S. private wage and salary employment

- Total private wage and salary employment in the ith industry in the U.S.

- Total U.S. merchandise exports

- Total regional private wage and salary employment

- Time

This part of the manpower demand model is discussed elsewhere so I will only briefly restate a few key points. ${ }^{2}$ Since the objective of the model is to forecast regional manpower demand, primary consideration is given to the predictive ability of the model. Thus it was not specified with the view of attempting to provide empirical verification of any given theory of regional growth. The model emphasizes the role of external demand in producing regional employment change. The model hypothesizes that a given structure of national and international demand for output will have specific employment effects on the region depending on its industrial structure. Independent variables $\mathrm{E}(\mathrm{UST}), \mathrm{E}(\mathrm{USI})_{\mathrm{i}}$, and $\mathrm{EX}$ are inserted in the model in order to simulate the employment effects of an assumed pattern of external demand on the individual regional industries. Independent variable E(REGT) was included in an attempt to incorporate the effect of local demand on regional production. The time variable was included as a proxy variable for other influences on regional industrial employment. The time variable could reflect the effects of changes in supply side location factors such as shifts in regional input cost differentials or technical change.

The regional industry forecasting model is also quite flexible. It can be used to obtain a wide variety of conditional forecasts based on alternative assumptions regarding national, international, and local demand. The model is specified so that it can be linked to any submodel capable of providing forecast values of the independent variables. This allows the policymaker to observe the regional employment effects of a variety of assumed patterns of external and local demand.

The regional industry regression model has been empirically estimated using Illinois as the study region. The statistical results were quite good as were the results of a short run accuracy test. ${ }^{3}$

The dependent variable of the industry regression model is private wage and salary employment in the ith regional industry. The dependent variable was specified in this way due to the absence of time series data for total employment in regional industries. Therefore, the forecast value of the dependent variable must be multiplied by the ratio of total employment to private wage and salary employ- 
ment for each industry. This multiplication results in the forecast value of total employment. Data to determine these industry ratios are available from the decennial Census of Population. Once the total employment forecast for each regional industry is obtained, they are inserted along the main diagonal of a diagonal matrix, called the $\mathrm{R}$ matrix. The $\mathrm{R}$ matrix is then post-multiplied by the industryoccupation matrix to obtain the regional manpower forecasts.

The industry-occupation matrix, the B matrix, has elements, bih. Each element indicates the portion of total employment in industry $\mathrm{i}$ composed of people classified in occupation $\mathrm{h}$. Let $\mathrm{i}=1,2, \ldots \mathrm{n}$; and $\mathrm{h}=1,1, \ldots \mathrm{k}$. Also $\sum_{\mathrm{h}=1}^{\mathrm{k}}$ bih $=1$. In other words, the occupational classification scheme is all inclusive and accounts for all the employment within the $\mathrm{n}$ industries. Post-multiplication of the $\mathrm{R}$ matrix by the $\mathrm{B}$ matrix results in the total occupation employment matrix, S. The elements, sih, of this matrix show the occupational employment requirements generated within each industry by the assumed pattern of external and local demand. The sums of the columns of the S matrix give the total employment generated in each regional occupation. This matrix multiplication may be written as:

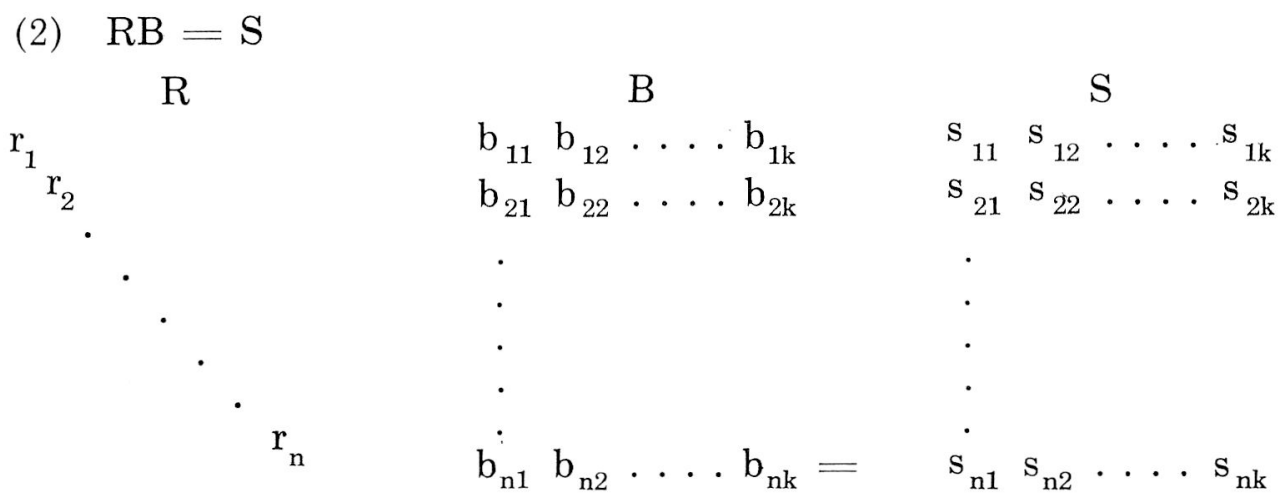

\section{THE REGIONAL INDUSTRY-OCCUPATION MATRIX}

There are several ways in which the regional industry-occupation matrix could be specified. Due to the lack of regional industry-occupation data, the BLS has recommended the use of a national industry-occupation matrix to make regional manpower forecasts. This procedure would yield reasonably accurate forecasts if the local industry-occupation patterns were similar to the national patterns. The BLS has performed a test of this assumption for the state of Ohio, and the conclusion was rough similarity in industry-occupation patterns. ${ }^{4}$ However, the test involved only one state and a limited number of occupations.

One factor influencing the validity of the similarity assumption would be the diversification of the state industrial structure. Intuitively it would seem that the similarity assumption might be more appropriate for industrially diversified states like Ohio, Illinois, New York, and California than states like Vermont, Maine, Utah, or Wyoming. Also the use of a national matrix might work reason- 
ably well for occupations employed in an industry which is highly concentrated in a particular state. For example the national industry-occupation coefficients of the automobile manufacturing industry are heavily influenced by the industryoccupation patterns of the auto industry in the state of Michigan. Thus the use of a national matrix to forecast occupational employment in the auto industry for the state of Michigan would probably yield reasonably accurate results. However, the use of the national matrix to make occupational forecasts in a state which may have only a few minor auto assembly plants would result in serious forecast errors.

Another source of occupational forecast error is the degree of industry disaggregation. For example the transportation equipment industry is composed of essentially four subindustries - motor vehicle manufacturing, aircraft and parts manufacturing, ship and boat building, and railroad equipment manufacturing. The industry-occupation pattern of the transportation equipment industry reflects the aggregate of the patterns found in the subindustries. This will lead to large forecast errors for some occupations if the region has no production in some of the subindustries. Thus if a certain region has no aircraft and parts manufacturing, the use of the national occupation pattern for the transportation equipment industry will generate erroneous employment demands for some occupations, such as aeronautical engineers, which are specialized to the aircraft and parts industry within the major category of transportation equipment.

In addition to these statistical factors, there are theoretical reasons for expecting dissimilarity between national and regional industry-occupation structures. Interregional factor immobility tends to perpetuate interregional factor price differentials resulting in interregional variations in production functions. Interregional differences in the incidence of technical change could also produce interregional variation in industry-occupation structure. So for both statistical and theoretical reasons, the possibility exists of making serious forecast error when using a national industry-occupation matrix to make regional occupational demand forecasts.

In view of the possibilities for making serious forecast errors in using a national industry-occupation matrix to make local occupation forecasts, a test was made of the similarity of regional and national industry-occupation patterns. The test was performed in the following manner:

(1) A diagonal matrix of 1970 Census estimates of employment in each state industry was post-multiplied by the 1970 national industry-occupation matrix. ${ }^{5}$ The columns of the resulting matrix (each column corresponding to an occupation or group of occupations) were summed. (2) The occupational employment estimates obtained using the national matrix (Step 1) were divided by the 1970 Census estimates of actual state employment in each occupation.

If the regional and national industry-occupation patterns are identical (or if coefficient differences exactly offset each other), then all the quotients calculated in Step 2 would equal 1 . Thus the degree of similarity between state and national industry-occupation structures can be determined by examining the degree to which the ratios depart from 1 . 
The test was performed for four states - Kansas, Colorado, Illinois, and California. The data for each state was obtained from the appropriate volume of Detailed Characteristics - 1970 Census of Population. ${ }^{6}$

The degree of similarity observed in any empirical test will be highly influenced by the level of industrial, occupational, and regional disaggregation. In general, the greater the degree of aggregation, the greater the similarity that will be observed by the test. The highly aggregated industrial and occupational categories represent composites of differing subcategories whose coefficient differences tend to cancel one another. The larger the region, the greater the degree of coefficient similarity since the national industry-occupation structures are composites of the industry-occupation patterns found in the subregions. The averaging of differences produced by regional aggregation results in the observance of greater similarity.

One of the major constraints on disaggregation in empirical tests is data availability. The 1970 national industry-occupation matrix published by the Census is highly aggregated. It has only 48 distinct industry categories and 81 occupational categories. However, the occupational categories are not distinct. The occupational classification scheme has three levels of aggregation. The highest level of aggregation contains 10 categories, an intermediate level has 58 categories, and 13 categories are in the third level of disaggregation. Thus the high level of aggregation biases the test toward a similarity conclusion.

Each of the ratios calculated in Step 2 of the above test was examined and the percentage deviation from 1 calculated. The results are compiled in Table 1 . An examination of Table 1 reveals that approximately $1 / 4$ of the ratios had a percentage deviation from 1 in excess of $20 \%$. This result makes it very difficult to accept the similarity hypothesis, especially given the high degree of aggregation. Seven of the ten most aggregated occupational categories had a percentage deviation of less than $10 \%$ in all four states. When these are removed from consideration, $27 \%$ of the occupational ratios had a percentage deviation greater than $20 \%$. In order to be useful for policy purposes, the occupational classification system would have to be much more disaggregated than the system used in this test. The use of a national matrix to make regional forecasts of manpower demand for a more disaggregated set of occupational categories would lead to forecast errors even larger than those suggested by the above test.

The regional industry-occupation matrix may also be specified by using regional decennial Census of Population data. The major disadvantage of this approach is the high degree of aggregation. The data is available for states and SMSA's exceeding 250,000 population, but for only 48 distinct industry categories and less than 81 distinct occupational categories. ${ }^{7}$ Many of the occupational categories include a wide variety of heterogeneous occupations (i.e., requiring different skills), rendering the forecasts of such groups essentially useless for policy purposes. To get an idea of the heterogeneous nature of many of the occupational categories, the following occupations are classified in the Other Clerical and Kindred Workers category. 
TABLE 1

\section{SIMILARITY OF NATIONAL AND REGIONAL INDUSTRY-OCCUPA- TION STRUCTURES SELECTED STATES — 1970}

Deviation of Ratio From 1

Less than 10 percent

10-19 percent

20-29 percent

30 percent and above

Deviation of Ratio From 1

Less than 10 percent

10-19 percent

20-29 percent

30 percent and above

Deviation of Ratio From 1

Less than 10 percent

10-19 percent

20-29 percent

30 percent and above

Deviation of Ratio From 1

Less than 10 percent

10-19 percent

20-29 percent

30 percent and above

Deviation of Ratio From 1

Less than 10 percent

10-19 percent

20-29 percent

30 percent and above
Kansas

Percent of Ratios $42 \%$

$23 \%$

$15 \%$

$20 \%$

Colorado

Percent of Ratios

$54 \%$

$22 \%$

$13 \%$

$11 \%$

Illinois

Percent of Ratios

$60 \%$

$25 \%$

$6 \%$

$9 \%$

California

Percent of Ratios

$46 \%$

$32 \%$

$11 \%$

$11 \%$

Average - All States

Percent of Ratios

$50 \%$

$26 \%$

$11 \%$

$13 \%$

Bank tellers; billing clerks; clerical assistants, social welfare; clerical supervisors, n.e.c.; collectors, bill and account; counter clerks, except food; dispatchers and starters, vehicle; enumerators and interviewers; expediters and production controllers; file clerks; insurance adjusters, examiners, and investigators; library attendants and assistants; mail carriers, post office; mailhandlers, except post office; messengers, including telegraph and office boys; meter readers, utilities; payroll and timekeeping clerks; postal clerks; proofreaders, real estate appraisers; receptionists; secretaries, stenographers, statistical clerks; teachers aides, except school 
monitors; telegraph operators; ticket, station and express agents; typists; weighers; miscellaneous clerical workers; not specified clerical workers.

The survey method is another alternative method of specifying the regional industry-occupation matrix. The data could be obtained by interviewing a representative sample of the firms in each regional industry and classifying the labor force by appropriate occupation. The major disadvantage of the survey method is the large time and money costs involved in generating one's own data. Often a year or more is required to gather the data before any forecasting can begin. However, the survey method offers the researcher the advantages of establishing his own classification scheme and disaggregating to the desired degree. The increased latitude in disaggregating the occupational categories has the advantage of making the model more useful for policy purposes.

Another method of specifying the regional industry-occupation matrix is to use local data to modify a forecast national matrix. This approach offers a compromise between the excessive aggregation of the Census data and the large time and money costs of the survey method. The BLS has devoted much research effort to developing forecast national matrices for 1980 and 1985. These national matrices have a fairly high degree of disaggregation,, both by industry and occupation. $^{8}$

These national matrices can be modified to reflect more closely local industry-occupation structures by using the following procedure.

(1) A diagonal matrix of 1970 Census of Population estimates of regional employment in each industry is post-multiplied by the 1970 national industryoccupation matrix. The columns of the resulting matrix (each column corresponding to an occupation or group of occupations) are summed.

(2) The 1970 Census estimates of actual regional employment in each occupation are divided by the occupational employment estimates obtained using the national matrix in Step 1.

If each column of the 1970 national matrix is multiplied by the appropriate ratio obtained in Step 2, a corrected national matrix is obtained. Then if the diagonal matrix of 1970 Census estimates of regional employment in each industry is post-multiplied by the corrected 1970 national matrix, the result will be actual 1970 regional employment in each occupation.

(3) The forecast regional matrix is obtained by multiplying each column of the forecast national matrix by the appropriate ratio obtained in Step 2.

This procedure simply measures the difference between local and national industry-occupation structures as of a specific point in time. Thus the use of this procedure to make regional manpower forecasts assumes that the coefficients of the local matrix change in the same direction as the national coefficients, but the degree of difference between the local and national coefficients remains constant into the prediction period.

Assuming that the researcher could obtain a well specified local industryoccupation matrix, as of a particular point in time, he would still have the problem 
of forecasting changes in the matrix coefficients. Theoretically, we know the coefficients will change over time in response to technical change, innovation, and input price changes. But the important question for forecasting purposes is how much of an effect such changes will have on the demand for specific occupations over a specified time period. Thus if the coefficients of the regional industry-occupation matrix are relatively stable over a five to ten year time span, reasonably accurate forecasts could be obtained by assuming that the coefficients remain constant into the prediction period. If the matrix coefficients are dynamically unstable over a five to ten year time span, some method of forecasting changes in the coefficients must be developed.

One possible approach to this would be to utilize a method that has been suggested for forecasting changes in regional input-output coefficients. This is the so called "best firm practice" approach. ${ }^{9}$ This procedure involves selecting a sample of "best practice" firms in each industry, using some efficiency measure such as output per man-hour. The forecast regional industry-occupation matrix would be compiled using the occupational employment patterns of the "best practice" firms. The assumption is that occupational employment structures of the most efficient firms at time $t$ will approximate the average occupational employment structure of all firms in the industry at time $t+k$. The major difficulty is discerning how rapidly the most efficient method of production will be diffused through the industry. Also there is the additional disadvantage of having to obtain the necessary data through the costly survey process.

Much research into the dynamic stability of regional industry-occupation structures needs to be done. This research would measure the degree of forecast error associated with the constant coefficients assumption for varying time spans. This type of study would also be quite helpful in identifying the prediction period for which reasonably accurate forecasts can be made when utilizing the constant coefficients assumption.

\section{REGIONAL SUPPLY "FEEDBACK” EFFECTS AND REGIONAL MANPOWER DEMAND}

As suggested above, technical change and input price changes have an important impact on the accuracy of manpower demand forecasts. Thus any regional manpower demand model would be greatly improved by integrating it with a regional manpower supply model, with the integrated system being capable of measuring the "feedback" effects resulting from changing demands.

Demand forecasts, which ignore supply feedback effects, assume that all supply schedules of all occupational skills are perfectly elastic. So when the demand for such skills changes, employment will change with no change in the wage rates. However, the supply schedules are not perfectly elastic, and the usual effect of a change in demand (supply constant) is to change the wage rate as well as employment.

The shifts in wage rates for various occupational skills will cause changes in the quantities demanded by individual firms depending on the factor elasticities 
of substitution. If the elasticity of substitution between capital and occupational skills and between occupational skills themselves is low, then the input price changes will result in a small demand response. However, high elasticities of substitution will produce large substitution effects on the demand side of the market.

Therefore, demand models, which ignore regional supply feedback effects, will experience better predictive performance the more elastic factor supply schedules are and the lower the factor elasticities of substitution. Of course, measurement of these supply effects and incorporation of them into a forecasting system of labor market adjustment is a difficult empirical task. However, failure to do so will tend to produce overestimates of changes in the employment demand for specific occupational skills.

\section{FOOTNOTES}

1. International exports should be in the equation only where theoretical considerations warrant its inclusion. Usually this would include regional industries in the agriculture, manufacturing, and mining sectors.

2. See M. W. Babcock, “An Urban-Regional Employment Demand Model," Review of Regional Studies, Vol. 4, No. 1 (Spring, 1974), pp. 1-10.

3. Ibid., pp. 3-7.

4. U.S. Department of Labor, Bureau of Labor Statistics, Tomorrow's Manpower Needs. (Washington, D.C.: U.S. Government Printing Office, 1969), Vol. I., pp. 13-17.

5. U.S. Department of Commerce, Bureau of the Cenus, 1970 Detailed Characteristics. Table 232. Occupation of Employed Persons by Industry Group and Sex: 1970 (Washington, D.C.: U.S. Government Printing Office, 1973).

6. U.S. Department of Commerce, Bureau of the Census, 1970 Detailed Characteristics, Table 180. Occupation of Employed Persons by Industry Group and Sex: 1970 (Washington, D.C.: U.S. Government Printing Office, 1973).

7. Ibid.

8. See U.S. Department of Labor, Bureau of Labor Statistics, Occupational Employment Patterns for 1960 and 1975. (Washington, D.C.: U.S. Government Printing Office, 1968), pp. 4-11.

9. See W. H. Miernyk, "Long Range Forecasting With a Regional Input-Output Model", Western Economic Journal, June 1968, pp. 165-176.

\section{REFERENCES}

1. Babcock, Michael W., Employment Implications of Alternate Federal Spending Priorities For the Illinois Economy, (Ph.D. thesis, Urbana, Illinois, 1973).

2. Babcock, Michael W. and Folk, H., "Future Employment in Illinois Industries, 1975 and 1980," Illinois Business Review, (March, 1973).

3. Babcock, Michael W., "An Urban-Regional Employment Demand Model," Review of Regional Studies, (Spring, 1974).

4. Bezdek, Roger H., Manpower Implications of Alternate Patterns of National Demand for Goods and Services, (Ph.D. thesis, Urbana, Illinois, 1971).

5. Dauffenbach, R. C., The Structure of Occupational Mobility in the U.S. Economy, (Ph.D. thesis, Urbana, Illinois, 1973).

6. Folk, H., "Manpower Research Alternatives and Imperatives," in The Production of Manpower Specialists, edited by J. R. Niland (Ithaca: New York State School of Industrial and Labor Relations, 1971).

7. Folk, H., The Shortage of Scientists and Engineers, (Lexington, Mass: D.C. Heath, 1970).

8. Illinois Department of Labor, Bureau of Employment Security, Occupational Manpower Requirements Projections for Illinois 1960-1975, (Chicago: 1970).

9. .................., Employment Outlook for Forty-Five Selected Occupations, (Chicago: 1973).

10. New York Department of Labor, Division of Research and Statistics, Manpower Requirements Interim Projections New York State 1968-1980, (New York, 1971).

11. Redwood, Anthony L., Population Projections for Manpower Planning, (Ph.D. thesis, Urbana, Illinois, 1972).

12. Richardson, H.W., "An Approach to Metropolitan Employment Forecasting," Review of Regional Studies, (Spring, 1971). 
13. Thiel, H., Economic Forecasts and Policy, (Amsterdam: North-Holland Publishing Co., 1965)

14. Udis, Bernard, Editor, Adjustments of the U.S. Economy to Reductions in Military Spending, (Washington, D.C.: U.S. Government Printing Office, 1970).

15. U.S. Department of Labor, Bureau of Labor Statistics, Occupational Employment Patterns for 1960 and 1975, Bulletin 1599, (Washington, D.C.: U.S. Government Printing Office, 1968).

16. ..............., Tomorrow's Manpower Needs, Bulletin 1606, four volumes, (Washington, D.C.: U.S. Government Printing Office, 1969).

17. ..............., Tomorrow's Manpower Needs, Vol. IV (Revised 1971), Bulletin 1737, (Washington, D.C.: U.S. Government Printing Office, 1972). 